\title{
Cellular transcriptional profiling in human lung epithelial cells infected by different subtypes of influenza $A$ viruses reveals an overall down-regulation of the host p53 pathway
}

Olivier Terrier ${ }^{1,2 \dagger}$, Laurence Josset ${ }^{1,3 \dagger}$, Julien Textoris ${ }^{4}$, Virginie Marcel ${ }^{2}$, Gaëlle Cartet ${ }^{1}$, Olivier Ferraris ${ }^{1}$, Catherine N'Guyen ${ }^{4}$, Bruno Lina ${ }^{1,3}$, Jean-Jacques Diaz ${ }^{5}$, Jean-Christophe Bourdon ${ }^{2}$ and Manuel Rosa-Calatrava ${ }^{1 *}$

\begin{abstract}
Background: Influenza viruses can modulate and hijack several cellular signalling pathways to efficiently support their replication. We recently investigated and compared the cellular gene expression profiles of human lung A549 cells infected by five different subtypes of human and avian influenza viruses (Josset et al. Plos One 2010). Using these transcriptomic data, we have focused our analysis on the modulation of the p53 pathway in response to influenza infection.
\end{abstract}

Results: Our results were supported by both RT-qPCR and western blot analyses and reveal multiple alterations of the p53 pathway during infection. A down-regulation of mRNA expression was observed for the main regulators of p53 protein stability during infection by the complete set of viruses tested, and a significant decrease in p53 mRNA expression was also observed in H5N1 infected cells. In addition, several p53 target genes were also downregulated by these influenza viruses and the expression of their product reduced.

Conclusions: Our data reveal that influenza viruses cause an overall down-regulation of the host p53 pathway and highlight this pathway and p53 protein itself as important viral targets in the altering of apoptotic processes and in cell-cycle regulation.

\section{Background}

Influenza viruses belong to the Orthomyxoviridae family of enveloped viruses containing a segmented genome of single stranded negative RNA. Among the three influenza types (A, B and $C$ ), type $A$ is the most virulent pathogen with a diversity represented by the combination of $16 \mathrm{H}$ and $9 \mathrm{~N}$ different subtypes (e.g. H1N1, H5N1) [1]. Influenza A viruses are the most serious threat to public health, with the potential to cause global pandemics as was illustrated in 2009 with the emergence of H1N1 SOIV [2].

All known subtypes of the influenza A virus are maintained in wild waterfowl, the natural reservoir of these

\footnotetext{
* Correspondence: manuel.rosa-calatrava@univ-lyon1.fr

† Contributed equally

'Laboratoire de Virologie et Pathologie Humaine VirPath, Université Claude Bernard Lyon 1, Université de Lyon, Lyon, France

Full list of author information is available at the end of the article
}

viruses [3]. Current human circulating influenza A subtypes are H1N1 and H3N2. While extensive viral diversity is responsible for the subtype-specific virus-host interactions, many common functional features are also shared among viruses. Influenza infection alters host cellular homeostasis via the combination of the virallyinduced alteration of biological machineries/pathways and the cellular antiviral response triggered by intracellular signalling cascades. Influenza viruses are able to activate/ inhibit and hijack several cellular signalling pathways to efficiently support their own replication [4].

The development of high-throughput 'omic' studies has increased our understanding of viral-host interactions. Numerous studies have described host gene expression modifications induced upon viral infection in vitro, in animal models and in patients [5-9]. For example, a global mRNA profiling study of MDCK-infected cells has revealed an important role of the NF-kappaB 
signalling pathway for the $\mathrm{H} 5 \mathrm{~N} 1$ subtype and to a lesser extent for the currently circulating H3N2 strain [10]. Other intracellular signalling cascades are also induced by infection, in particular the mitogen-activated protein kinase (MAPK) and the PI3K/Akt pathways, both of which activate downstream transcription factors thereby affecting host gene expression [11,12]. While a small number of transcriptional studies have compared the cellular response induced by infection with highly pathogenic strains such as H1N1 1918 and H5N1 to that induced with low pathogenic strains, a systematic analysis and comparison of host cell mRNA expression during infection by several genetically diverging influenza subtypes has not yet been performed $[7,8,13,14]$.

Using a nylon microarray, we recently characterized common gene expression changes induced during the infection of human lung epithelial cells by five different influenza A viruses. This shared signature was exploited to find new molecules that act on host metabolic pathways to bring about an antiviral effect against several subtypes [15]. Moreover, our systematic transcriptomic study also provided a gene expression database with which we compared the cellular responses induced by different influenza viruses. In the present study, we used the same data set to analyze strain specificity in regard to several host pathways. We observed that each viral signature was mainly associated with cellular pathways linked to cell death and cell cycle progression (i.e. cell growth). At the crossroads of all of these cellular processes, the p53 pathway became the focus of our investigation. Our analyses, validated by both RT-qPCR and western blot analyses, reveal multiple alterations within the p53 pathway during influenza A infection.

\section{Methods}

\section{Cell lines, viruses and infection}

Human lung epithelial A549 cells (ATCC CCL-185) or human colon carcinoma HCT116 cell lines were grown as monolayers in Dulbecco's modified Eagle's medium (DMEM, Gibco), supplemented with 10\% heat-inactivated foetal bovine serum, $2 \mathrm{mM}$ L-glutamine, $100 \mathrm{U} / \mathrm{mL}$ of penicillin and $100 \mathrm{mg} / \mathrm{mL}$ of streptomycin sulphate, at $37^{\circ} \mathrm{C}$. The HCT116 cell lines containing a p53 wild-type (p53+/+) and a p53-deleted derivative (p53-/-) were gifts from Dr. Bert Vogelstein (John Hopkins University, Baltimore, MD, USA) [16]. Influenza viruses A/New Caledonia/20/99 (H1N1), A/Moscow/10/99 (H3N2), A/Lyon/ 969/09 (H1N1 SOIV), A/Turkey/582/2006 (H5N1), A/Finch/England/2051/94 (H5N2), and A/Chicken/Italy/ 2076/99 (H7N1) were produced in MDCK cells in EMEM supplemented with $2 \mathrm{mM} \mathrm{L}$-glutamine, $100 \mathrm{U} / \mathrm{mL}$ of penicillin, $100 \mathrm{mg} / \mathrm{mL}$ of streptomycin sulphate and $1 \mathrm{mg} / \mathrm{mL}$ of trypsin. Viruses were titrated to determine the $50 \%$ tissue culture infective dose (TCID50) in MDCK cells as described in our previous study [17]. Confluent A549 cells were infected with influenza viruses at a MOI of 1 or 10-3 for one hour in a minimal volume of DMEM supplemented with $2 \mathrm{mM} \mathrm{L}$-glutamine, $100 \mathrm{U}$ of penicillin $/ \mathrm{mL}$, $100 \mu \mathrm{g}$ of streptomycin sulphate $/ \mathrm{mL}$ and $0.5 \mu \mathrm{g}$ of trypsin/ $\mathrm{mL}$ (infection medium) at $37^{\circ} \mathrm{C}$. The cells were then overlaid with fresh infection medium and incubated at $37^{\circ} \mathrm{C}$ for $24 \mathrm{~h}$. Viral kinetics for the six different influenza viruses have been determined previously [15]. No markers of apoptosis were detected at $24 \mathrm{~h}$ post infection (MOI 1) by western blot (capspase 3 cleavage) and no signs of cell death were observed (data not shown).

\section{Microarray analysis}

Gene expression data of A549 cells infected by H1N1, $\mathrm{H} 3 \mathrm{~N} 2, \mathrm{H} 5 \mathrm{~N} 1, \mathrm{H} 5 \mathrm{~N} 2$ or H7N1 influenza viruses or mock infected (five replicates in each group) were obtained in our previous study [15]. Data sets are available publicly from the Gene Expression Omnibus (GEO) database (http://www.ncbi.nlm.nih.gov/geo/) under accession number GSE22319. Five supervised analyses between groups of infected versus mock samples were conducted using the Significance Analysis of Microarray algorithm (SAM) [18], and the siggenes library (v1.18.0) [19]. Ingenuity Pathway Analysis 5.0 (IPA) (Ingenuity Systems, Redwood City, CA, USA) was used to select, annotate, and visualize genes according to function and pathway (Gene Ontology). Additional gene annotation was provided by the Interferome Database [20] and DAVID database (http://david.abcc.ncifcrf.gov/). Heat maps were produced by the heat map function from $\mathrm{R}$ that uses hierarchical clustering with Euclidean distance metric and the complete linkage method to generate the hierarchical tree (http://www.r-project.org/).

\section{Validation by RT-qPCR}

Total RNAs were extracted using the RNAeasy Mini Kit (Qiagen). Reverse-transcription was performed on $1 \mu \mathrm{g}$ of total RNAs using the Superscript II enzyme (Invitrogen) at $42^{\circ} \mathrm{C}$. Quantification of the level of different mRNAs of interest was performed by real-time PCR on a MX3005P apparatus (Stratagene). Briefly, $20 \mathrm{ng}$ of cDNAs were amplified using $0.8 \mu \mathrm{M}$ of each primer, $0.4 \mu \mathrm{M}$ of probe (cf. Table 1) and 1X Taqman Universal Master Mix (Applied Biosystems). All data were normalized to the internal standard Actin. For each single-well amplification reaction, a threshold cycle $(\mathrm{Ct})$ was observed in the exponential phase of amplification. Relative changes in gene expression were determined using the $2 \Delta \Delta \mathrm{Ct}$ method and reported as the $\mathrm{n}$-fold difference relative to a control cDNA (mock, uninfected cells) prepared in parallel with the experimental cDNAs (infected cells) [21]. The mRNA levels were measured in triplicate in two independent experiments. Quantification of $M$ 
Table 1 List of primers used in this study

\begin{tabular}{|c|c|c|}
\hline \multicolumn{2}{|c|}{ Primers \& probes } & \multirow{2}{*}{$\frac{\text { Sequence } \mathbf{5}^{\prime} \text {-3' }}{\text { GAA GAG AAT CTC CGC AAG AAA GG }}$} \\
\hline p53 (Exon8-9) & Forward & \\
\hline & Reverse & TCC ATC CAG TGG TाT CTT CTT TG \\
\hline & Probe & AGC ACT AAG CGA GCA CTG CCC AAC \\
\hline \multirow[t]{3}{*}{ p21 } & Forward & GACTCTCAGGGTCGAAAACGG \\
\hline & Reverse & GCGGATTAGGGCTTCCTCTT \\
\hline & Probe & CTACCACTCCAAACGCCGGCTGATCT \\
\hline \multirow[t]{3}{*}{ Bax } & Forward & ACTCCCCCCGAGAGGTCTT \\
\hline & Reverse & GCAAAGTAGAAAAGGGCGACAA \\
\hline & Probe & GAGCTGACATGTITTCTGACGGCAACTTCAACT \\
\hline \multirow[t]{3}{*}{$\mathrm{BCl}-\mathrm{XL}$} & Forward & TCC TTG TCT AGG CTT TCC ACG \\
\hline & Reverse & GGT CGC ATT CTC GCC TTT \\
\hline & Probe & ACA GTG CCC CGC CGA AGG AGA \\
\hline \multirow[t]{3}{*}{ Influenza M } & Forward & CTTCTAACCGAGGTCGAAACGTA \\
\hline & Reverse & GGTGACAGGATTGGTCTTGTCTTAA \\
\hline & Probe & TCAGGCCCCCTCAAAGCCGAG \\
\hline
\end{tabular}

viral genome copies released in supernatants was performed according to previously published work [22].

\section{Western blot analysis}

Total proteins were extracted by scraping and syringing cells in 1X NuPAGE LDS buffer (Invitrogen). Fifteen to thirteen micrograms of total proteins were then separated on pre-cast $10 \%$ NuPAGE gels (Invitrogen). To detect the different proteins of interest, the following antibodies were used: mouse monoclonal DO-1 (p53) and SX118 (p21, Cell signalling), Rabbit polyclonals Bax, Akt and Bcl-XL (Cell signaling). The mouse monoclonal Ku80 antibody was used as a loading control (Abcam). The relative protein levels (RPL) were calculated by densitometry analysis performed with the help of the ImageJ software (http://rsbweb.nih.gov/ij/).

\section{Results}

\section{Specific viral signatures and commonly targeted host genes}

We have previously reported variations in gene expression at $24 \mathrm{~h}$ post-infection in human pulmonary epithelial A549 cells infected with different subtypes of influenza viruses: human A/New Caledonia/20/99 (H1N1), A/Moscow/10/99 (H3N2), avian A/Turkey/582/ 2006 (H5N1), A/Finch/England/2051/94 (H5N2), A/ Chicken/Italy/2076/99 (H7N1) influenza viral strains or mock control infection (five replicates in each group) [15]. Compared to the mock control infection, changes were observed in 36 cellular genes for H1N1, 2298 genes for H3N2, 1455 genes for H5N1, 1510 genes for H5N2 and 3020 genes for H7N1 (SAM algorithm with a False Discovery Rate of 10\%). The small changes induced upon H1N1 infection were correlated to its low level of replication in our experimental conditions [15]. While $83 \%$ of the host genes altered following H1N1 infection were over-expressed, a similar number of genes were over-and under-expressed for each of the other viruses (figure 1A). Furthermore, we found that the expression levels for a total of 300 genes (representing $3.4 \%$ of the genes considered present on the chip) differed significantly between mock and all infected samples including H1N1 [15].

To determine the specific cellular genes showing altered expression within each of the different strainspecific signatures, we built the Venn diagram shown in figure 1B. Common changes in the expression of numerous genes (1007) were induced by three of the viruses, H3N2, H5N2 and H7N1. The expression of 705 of these genes was also altered when four viruses were considered: H3N2, H5N1, H5N2 and H7N1. Since H1N1 deregulated only a small number of genes, the number of those the expression of which was modified by all strains was limited to 20 . Their associated biological responses were described in our previous study and are mainly linked to the immune response in accordance with other investigations [15].

\section{Biological processes associated with each viral signature} We then determined the Gene Ontology (GO) biological processes (or terms) significantly associated with each viral signature using the DAVID database. With a
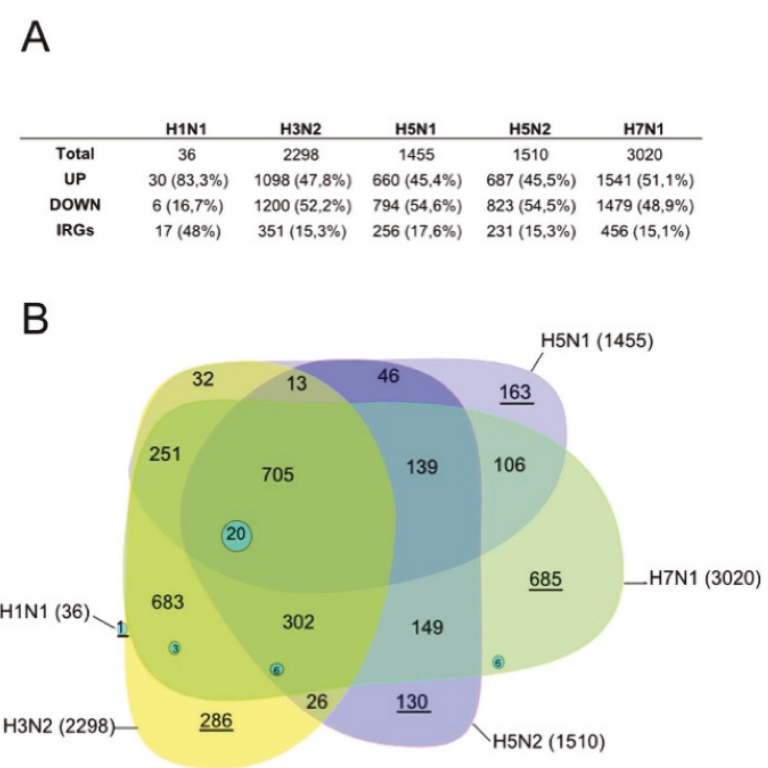

Figure 1 Summary of genes expressed in response to $\mathrm{H} 1 \mathrm{~N} 1$, H3N2, H5N1, H5N2 and H7N1 viral infection. A. Genes significantly regulated (SAM, FDR $=10 \%$ ) in response to the different influenza viruses compared to mock infection at $24 \mathrm{hpi}$ are shown. B. Venn-diagram showing the genes co-regulated by several viruses 
p-value $<0.01$, no one term was shared among the five viruses. The 36 genes deregulated upon H1N1 infection encode proteins involved in the cellular immune response, transcription, biogenesis of protein complexes and nucleic acid metabolic processes. In contrast, the signatures of $\mathrm{H} 3 \mathrm{~N} 2, \mathrm{H} 5 \mathrm{~N} 1, \mathrm{H} 5 \mathrm{~N} 2$ and $\mathrm{H} 7 \mathrm{~N} 1$ viruses were each associated with 33 common terms (p-value $<0.01$ ) (figure 2), covering all the biological processes of DAVID database. Two major classes of biological processes could be distinguished. Firstly, there are those that are affected by the four viral strains through the modulation of a common gene subset. For example, each of the viral strains modulated the expression of 10 common genes involved in the glucose catabolic process", while only a few genes involved in this process were differentially modulated in a strain-dependent manner. Secondly, there are those that are affected by each of the four viral strains through the modulation of distinct gene subsets in a strain-dependent manner. For example, while 35 genes all associated with the "apoptosis" process were modulated by the four viruses, 11 of these were specifically modified upon H3N2 infection, 11 by $\mathrm{H} 5 \mathrm{~N} 1,7$ by $\mathrm{H} 5 \mathrm{~N} 2$ and 35 by H7N1.

Among the 33 common terms associated with the viral signatures, more than $60 \%(n=20)$ were related to the control of cell death or cell cycle progression. Other common biological processes were related to angiogenesis, protein complex biogenesis or metabolism [15]. Interestingly, despite the abovementioned current association made between influenza virus-induced host cell responses and the cellular immune response, we found no terms shared by all viruses relating to the immune response. Moreover, by consulting the whole list of biological processes associated to each virus signature we found the term "immune response" significantly mapped to each viral profile, except for the H5N2 virus. However, the comparison of our differentially expressed gene lists to Interferome, an IFN-regulated gene database, revealed that a similar proportion of genes regulated upon infection by $\mathrm{H} 3 \mathrm{~N} 2, \mathrm{H} 5 \mathrm{~N} 1, \mathrm{H} 5 \mathrm{~N} 2$ or $\mathrm{H} 7 \mathrm{~N} 1$ (around 15\%) was related to the IFN response, whereas $48 \%$ of the genes responding to H1N1 infection were regulated by IFN [20].

In summary, analysis of our data showed that more than half of the genes responding to infection by H3N2, $\mathrm{H} 5 \mathrm{~N} 1, \mathrm{H} 5 \mathrm{~N} 2$ and $\mathrm{H} 7 \mathrm{~N} 1$ viruses, are involved in cell death, cell cycle progression or the cellular immune response. All these biological processes are regulated by a central signalling pathway, the p53 pathway [23]. Indeed, in addition to regulating the expression of genes involved in apoptosis and cell cycle arrest, p53 also regulates the expression of type I IFN as well as several genes carrying IFN-stimulated response elements [24]. For these reasons, and in light of several proposals of p53 being a functional interactant of influenza [25-27], we focused our investigations on modifications of the p53 pathway in response to influenza infection.

\section{Infection induces a transcriptional down-regulation of the upstream signal part of the p53 pathway}

In response to stress, such as viral infection, several signalling mediators relay the stress stimuli to the p53

\begin{tabular}{|c|c|c|c|c|c|c|c|c|c|}
\hline \multirow[b]{2}{*}{ Term } & \multicolumn{4}{|c|}{ Total Number of genes in each viral signature (p-value) } & \multirow{2}{*}{$\begin{array}{c}\text { common } \\
\text { genes }\end{array}$} & \multicolumn{4}{|c|}{ Number of genes unique to each signature } \\
\hline & H3N2 & H5N1 & H5N2 & H7N1 & & H3N2 & H5N1 & H5N2 & H7N1 \\
\hline GO:0001558 regulation of cell growth & $51(8.70-05)$ & $38(5.00-05)$ & $33(8.00-05)$ & $63(3.80-05)$ & 18 & 5 & 5 & 1 & 12 \\
\hline G0:0001568 blood vessel development & $67(1.40-06)$ & $43(2.00-04)$ & $34(2.50-03)$ & $85(6.10-08)$ & 12 & 11 & 1 & 3 & 18 \\
\hline G0:0001944 vasculature development & $68(1.6 \mathrm{e}-06)$ & $43(3.5 \mathrm{e}-04)$ & $34(3.7 \mathrm{e}-03)$ & $87(4.4 \mathrm{e}-08)$ & 12 & 11 & 1 & 3 & 19 \\
\hline GO:0006007 qlucose catabolic process & $19(1.8 \mathrm{e}-03)$ & $13(9.1 \mathrm{e}-03)$ & $13(2.0 \mathrm{e}-03)$ & $22(2.7 \mathrm{e}-03)$ & 10 & 2 & 0 & 0 & 4 \\
\hline GO:0006461 protein complex assembly & $104(8.9 \mathrm{e}-04)$ & $72(9.7 \mathrm{e}-04)$ & $61(1.6 \mathrm{e}-03)$ & $139(2.0 \mathrm{e}-05)$ & 27 & 13 & 7 & 5 & 33 \\
\hline G0.0006915 apoptosis & $124(2.8 \mathrm{e}-04)$ & $83(1.1 \mathrm{e}-03)$ & $69(2.8 \mathrm{e}-03)$ & $158(8.1 \mathrm{e}-05)$ & 35 & 11 & 11 & 7 & 36 \\
\hline GO:0006916 anti-apoptosis & $57(6.3 e-06)$ & $32(9.7 \mathrm{e}-03)$ & $32(5.5 \mathrm{e}-04)$ & $68(1.0 \mathrm{e}-05)$ & 15 & 6 & 4 & 1 & 10 \\
\hline GO:0006917 induction of apoptosis & $77(3.4 \mathrm{e}-05)$ & $50(9.5 e-04)$ & $42(2.10-03)$ & $106(2.00-08)$ & 18 & 6 & 7 & 4 & 26 \\
\hline GO:0007010 cytoskeleton organization & $93(5.3 \mathrm{e}-04)$ & $77(3.3 \mathrm{e}-07)$ & $54(1.7 \mathrm{e}-03)$ & $118(1.90-04)$ & 30 & 8 & 10 & 3 & 21 \\
\hline G0:0007049 cell cycle & $168(9.90-07)$ & $125(1.30-08)$ & $84(4.7 e-03)$ & $206(2.60-06)$ & 41 & 21 & 17 & 5 & 39 \\
\hline GO:0007243 protein kinase cascade & $83(2.10-04)$ & $55(1.6 \mathrm{e}-03)$ & $60(3.0 \mathrm{e}-07)$ & $117(6.5 \mathrm{e}-08)$ & 26 & 9 & 5 & 4 & 19 \\
\hline GO:0008219-cell death & $149(4.6 \mathrm{e}-05)$ & $101(1.5 \mathrm{e}-04)$ & $81(1.9 \mathrm{e}-03)$ & $192(4.0 \mathrm{e}-06)$ & 41 & 14 & 12 & 7 & 45 \\
\hline G0:0008361 regulation of cell size & $53(1.1 \mathrm{e}-04)$ & $36(7.9 \mathrm{e}-04)$ & $32(5.5 \mathrm{e}-04)$ & $61(8.1 \mathrm{e}-04)$ & 18 & 6 & 5 & 1 & 11 \\
\hline GO:0010941 regulation of cell death & $202(2.7 \mathrm{e}-13)$ & $128(4.1 e-08)$ & $113(1.1 \mathrm{e}-08)$ & $255(1.3 e-15)$ & 57 & 18 & 18 & 7 & 44 \\
\hline GO:0010942 positive regulation of cell death & $111(2.0 \mathrm{e}-08)$ & $71(1.7 \mathrm{e}-05)$ & $59(9.9 e-05)$ & $147(5.2 \mathrm{e}-12)$ & 31 & 9 & 8 & 4 & 33 \\
\hline GO:0012501 programmed cell death & $127(1.6 \mathrm{e}-04)$ & $86(4.5 \mathrm{e}-04)$ & $71(1.7 \mathrm{e}-03)$ & $162(3.7 \theta-05)$ & 37 & 11 & 11 & 7 & 37 \\
\hline GO:0012502 induction of programmed cell death & $77(3.8 \mathrm{e}-05)$ & $50(1.00-03)$ & $42(2.30-03)$ & $106(2.5 \mathrm{e}-08)$ & 18 & 6 & 7 & 4 & 26 \\
\hline GO:0016265 death & $150(4.5 \mathrm{e}-05)$ & $104(4.70-05)$ & $82(1.50-03)$ & $193(4.30-06)$ & 42 & 14 & 14 & 7 & 45 \\
\hline GO:0030155 regulation of cell adhesion & $35(2.2 \mathrm{e}-03)$ & $27(6.8 \mathrm{e}-04)$ & $24(6.0 \mathrm{e}-04)$ & $42(3.0 \mathrm{e}-03)$ & 13 & 7 & 5 & 2 & 8 \\
\hline G0:0032535 regulation of cellular component size & $65(1.6 \mathrm{e}-04)$ & $40(8.6 \mathrm{e}-03)$ & $37(2.10-03)$ & $78(3.8 \mathrm{e}-04)$ & 18 & 7 & 5 & 2 & 16 \\
\hline GO:0033554 cellular response to stress & $118(2.4 \mathrm{e}-04)$ & $85(5.5 \mathrm{e}-05)$ & $72(1.2 \mathrm{e}-04)$ & $150(7.6 \mathrm{e}-05)$ & 38 & 14 & 15 & 3 & 32 \\
\hline G0:0040008 regulation of growhh & $88(4.1 \mathrm{e}-07)$ & $58(3.4 \mathrm{e}-05)$ & $53(5.8 \mathrm{e}-06)$ & $101(1.4 \mathrm{e}-05)$ & 27 & 10 & 10 & 5 & 18 \\
\hline GO:0042981 regulation of apoptosis & $198(9.3 \mathrm{e}-13)$ & $127(3.3 \mathrm{e}-08)$ & $112(9.4 \mathrm{e}-09)$ & $250(5.9 e-15)$ & 56 & 18 & 18 & 7 & 43 \\
\hline G0:0043065 positive regulation of apoptosis & $110(2.1 \mathrm{e}-08)$ & $71(1.1 \mathrm{e}-05)$ & $59(7.1 \mathrm{e}-05)$ & $146(4.1 \mathrm{e}-12)$ & 31 & 9 & 8 & 4 & 33 \\
\hline GO 0043066 negative regulation of apoptosis & $86(7.70 .06)$ & $52(2.90-03)$ & $51(6.90-05)$ & $109(8.20-07)$ & 20 & 8 & 10 & 5 & 15 \\
\hline GO:0043067 regulation of programmed cell death & $201(3.6 \mathrm{e}-13)$ & $128(3.39-08)$ & $113(8.5 \mathrm{e}-09)$ & $253(3.00-15)$ & 57 & 18 & 18 & 7 & 43 \\
\hline G0:0043068 positive regulation of programmed cell death & $110(3.1 \mathrm{e}-08)$ & $71(1.4 \mathrm{e}-05)$ & $59(8.7 e-05)$ & $146(7.4 \mathrm{e}-12)$ & 31 & 9 & 8 & 4 & 33 \\
\hline GO:0043069 negative regulation of programmed cell death & $88(4.1 \mathrm{e}-06)$ & $52(3.9 \mathrm{e}-03)$ & $51(1.0 \mathrm{e}-04)$ & $111(5.1 e-07)$ & 20 & 8 & 10 & 5 & 15 \\
\hline GO:0043933 - macromolecular complex subunit organization & $146(8.2 \mathrm{e}-05)$ & $92(3.7 \mathrm{e}-03)$ & $76(9.4 \mathrm{e}-03)$ & $187(1.4 \mathrm{e}-05)$ & 35 & 20 & 10 & 5 & 45 \\
\hline GO:0046907 intracellular transport & $129(1.5 \mathrm{e}-03)$ & $84(8.2 \mathrm{e}-03)$ & $73(4.6 \mathrm{e}-03)$ & $171(6.5 e-05)$ & 35 & 12 & 9 & 5 & 40 \\
\hline GO:0048514 blood vessel morphogenesis & $59(3.0 \mathrm{e}-06)$ & $39(1.4 \mathrm{e}-04)$ & $30(3.3 e-03)$ & $77(2.5 \mathrm{e}-08)$ & 11 & 9 & 1 & 3 & 17 \\
\hline G0:0060548 negative regulation of cell death & $88(4.6 \mathrm{e}-06)$ & $52(4.1 \mathrm{e}-03)$ & $51(1.1 \mathrm{e}-04)$ & $112(3.2 \mathrm{e}-07)$ & 20 & 8 & 10 & 5 & 16 \\
\hline GO:0070271 protein complex biogenesis & $104(8.9 \mathrm{e}-04)$ & $72(9.7 \mathrm{e}-04)$ & $61(1.6 \mathrm{e}-03)$ & $139(2.0 \mathrm{e}-05)$ & 27 & 13 & 7 & 5 & 33 \\
\hline
\end{tabular}


protein, which is consequently stabilized and activated mainly by post-translational modifications including phosphorylations and acetylations [28]. Such modifications disrupt interactions between p53 and the ubiquitin ligase $\mathrm{Hdm} 2$, responsible for the rapid degradation of p53 in basal conditions [29,30]. Once activated, p53 regulates cell cycle arrest and apoptosis through the direct modulation of host cellular gene expression.

We firstly focused our attention on the upstream signal part of the p53 pathway. According to our data, all the main kinases known to directly regulate $\mathrm{p} 53$ phosphorylation status (DNA-PK, Chk2, JNK1 and Gsk3 $\beta$ ) are under-expressed following infection by $\mathrm{H} 3 \mathrm{~N} 2$, $\mathrm{H} 5 \mathrm{~N} 1, \mathrm{H} 5 \mathrm{~N} 2$ and $\mathrm{H} 7 \mathrm{~N} 1$ viruses (figure 3). For example, $\mathrm{n}$-fold $D N A-P K$ mRNA changes of $-1.78,-2.12,-1.41$ and -1.56 were measured for $\mathrm{H} 3 \mathrm{~N} 2, \mathrm{H} 5 \mathrm{~N} 1, \mathrm{H} 5 \mathrm{~N} 2$ and $\mathrm{H} 7 \mathrm{~N} 1$, respectively (figure 3 ). We also focused our attention on the phosphatidylinositol 3-kinase (PI3K)/ Akt pathway, which directly regulates $\mathrm{Hdm} 2$ expression and thus endogenous p53 activity [31]. Interestingly, our results indicate a decreased expression of both $A K T 1$ and its negative regulator PTEN (figure 3 ). These results are in accordance with the activation of the phosphatidylinositol 3-kinase (PI3K)/Akt pathway during influenza infection, as already described in the literature [32].

Altogether, our results reveal that influenza A infection induces the transcriptional down-regulation of several genes encoding host factors belonging to the upstream signal part of the p53 pathway and which act on the endogenous activity of p53.

\section{Differential effects of influenza viruses on p53 mRNA and protein levels}

Secondly, we assessed whether viral infection could also directly affect p53 mRNA expression. Interestingly, our data indicates that only one of the investigated viruses, $\mathrm{H} 5 \mathrm{~N} 1$, led to a significant decrease in the level of p53 mRNA expression, with a fold change of -1.54 (figure 3 ).

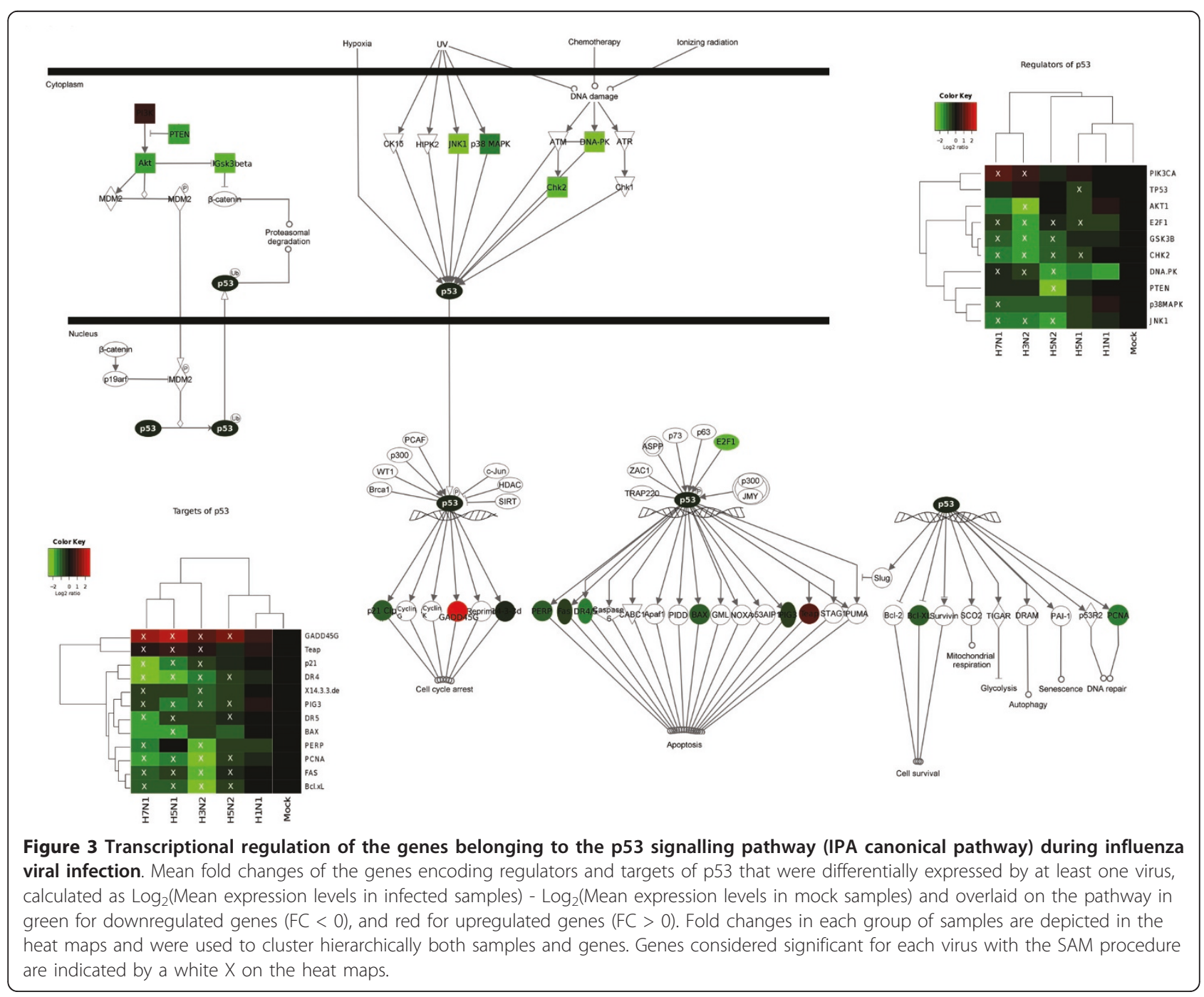


To assess such differential data, we infected another set of A549 cells with the different viruses used in our initial microarray study, including the low replicative H1N1 virus to which we added the recent pandemic H1N1 SOIV as an efficient productive H1N1 virus [28]. Total cell RNA was extracted 24 hours post-infection, similarly to that performed for the microarray analysis. The quantification of p53 mRNA levels was carried out by RTqPCR using primers matching several different EST sequences used in the microarray chip. In accordance with our previous data, no significant change in the p53 mRNA ratio was detected with $\mathrm{H} 3 \mathrm{~N} 2, \mathrm{H} 5 \mathrm{~N} 2$ and $\mathrm{H} 7 \mathrm{~N} 1$, nor with $\mathrm{H} 1 \mathrm{~N} 1$ or H1N1 SOIV, while a significant ratio change of 0.70 was observed in H5N1 infected cells ( $\mathrm{p}<$ 0.0005 , figure $4 \mathrm{~A}$ ). The calculated fold change was -1.43 , indicating the specific down-regulation of p53 mRNA expression in the context of H5N1 infection.

We further investigated whether such influenzainduced variations in p53 mRNA levels could be correlated or not with changes in the endogenous p53 protein level. For that, we reproduced the same experimental conditions as described above and performed western blots on infected cellular extracts. Compared to mock-infected cells, the p53 protein levels (Relative

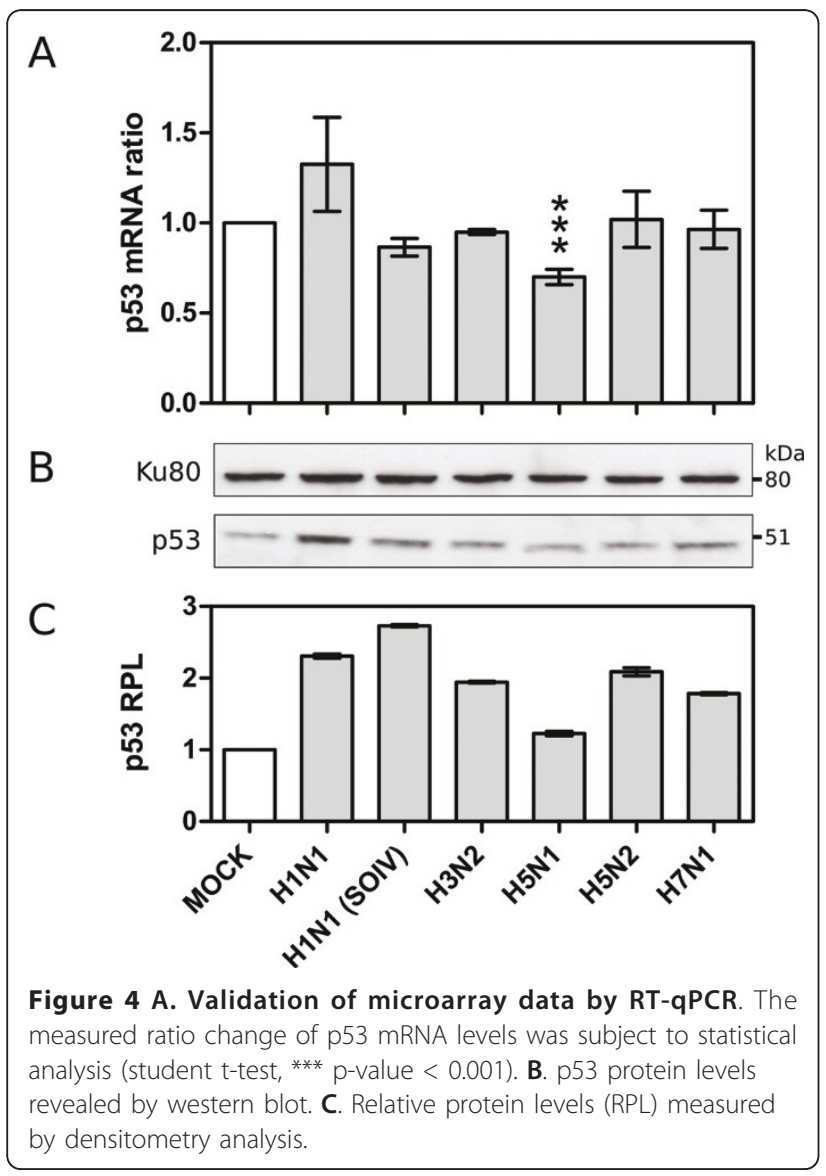

Protein Level, RPL) measured by densitometry analysis were significantly increased in cells infected by all the viruses studied, with a 1.78 to 2.72 fold increase for respectively $\mathrm{H} 7 \mathrm{~N} 1$ and $\mathrm{H} 1 \mathrm{~N} 1$ (SOIV), and a smaller 1.22 fold increase for H5N1 (figure 4B and 4C).

Our data further support the previously reported noncorrelation between p53 mRNA and protein levels in response to influenza infection, and are also in line with several other investigations reporting such a mismatch in the context of other cellular stresses [33]. Moreover, our results reveal an interesting contrast between $\mathrm{H} 5 \mathrm{~N} 1$ and the other viruses. Indeed, $\mathrm{H} 5 \mathrm{~N} 1$ infection directly affects the p53 mRNA expression level, accounting for the attenuated increase in the p53 protein level observed in the H5N1 infected cell.

\section{Transcriptional down-regulation of downstream signalling of the p53 pathway upon infection}

Having determined an increase in p53 protein levels during the time-course of infection, we then focused our attention on the expression of p53 downstream target genes. While several studies have previously shown an increase in p53 transcriptional activity during influenza virus infection by luciferase assay or the detection of phosphorylated p53 in infected cells [25,34], we observed in our experimental conditions a significant decrease in the transcriptional expression of several p53-targets genes during infection by H3N2, H5N1, $\mathrm{H} 5 \mathrm{~N} 2$ and $\mathrm{H} 7 \mathrm{~N} 1$ viruses (figure 3). These down-regulated genes include $p 21,14-3-3, P E R P, F A S, D R 4 / 5$, PIG3, BAX, Bcl-XL, PAI-1 and PCNA. For $\mathrm{p} 21$ (CDKN1A) for example, the $\mathrm{n}$-fold mRNA changes measured were $-1.81,-2.0$ and -1.85 for H3N2, H5N1 and H7N1 infections, respectively. The expression of only two p53-target genes investigated, Teap (TP53INP1), and GADD45G was increased upon infection by the 4 viruses (figure 3). The GADD45G n-fold mRNA changes measured were 1.61, 1.70, 1.26 and 1.60 for H3N2, $\mathrm{H} 5 \mathrm{~N} 1, \mathrm{H} 5 \mathrm{~N} 2$ and $\mathrm{H} 7 \mathrm{~N} 1$, respectively. It should be noted that TP53INP1 is also known to be regulated by p73, a p53 homologous protein, and must therefore be also regulated in a p53-independent manner [35].

To support these results, another set of A549 cells were infected with the broad set of viruses for $24 \mathrm{hpi}$ and variations of endogenous $\mathrm{p} 21, \mathrm{Bax}$ and Bcl-XL mRNA expressions and protein levels were analyzed in parallel by RT-qPCR and western blot, respectively (figure 5A, B and 5C). For p21, the mRNA level was significantly reduced only in $\mathrm{H} 5 \mathrm{~N} 1$-infected samples $(\mathrm{p}<0.05$, mRNA ratio around 0.2$)$, while the protein levels were reduced in cells infected by almost all the viruses studied (figure 5A). Moreover, a down-regulation of $\mathrm{Bax}$ expression was also clearly observed with significantly reduced mRNA levels in all infected cells, despite 


\section{A}

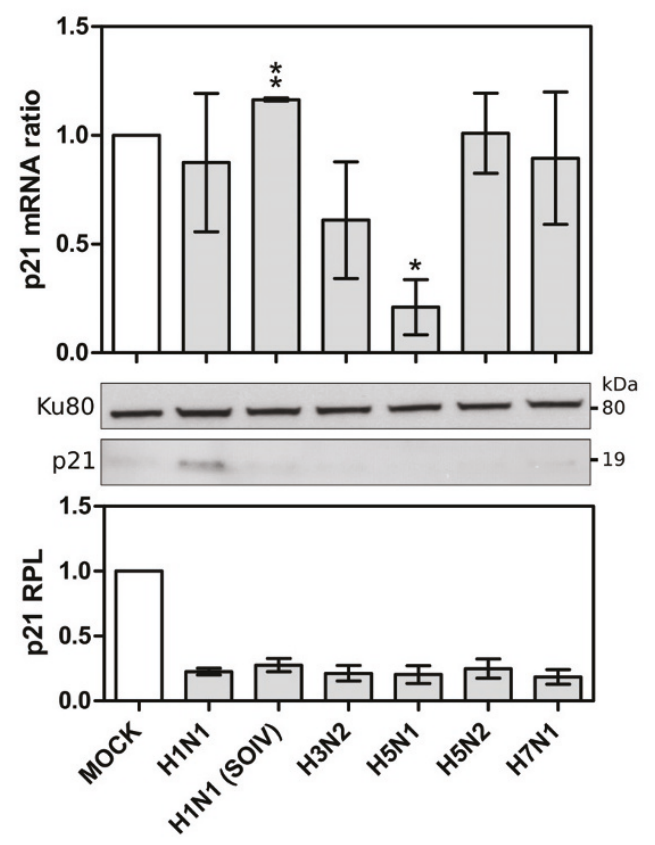

B
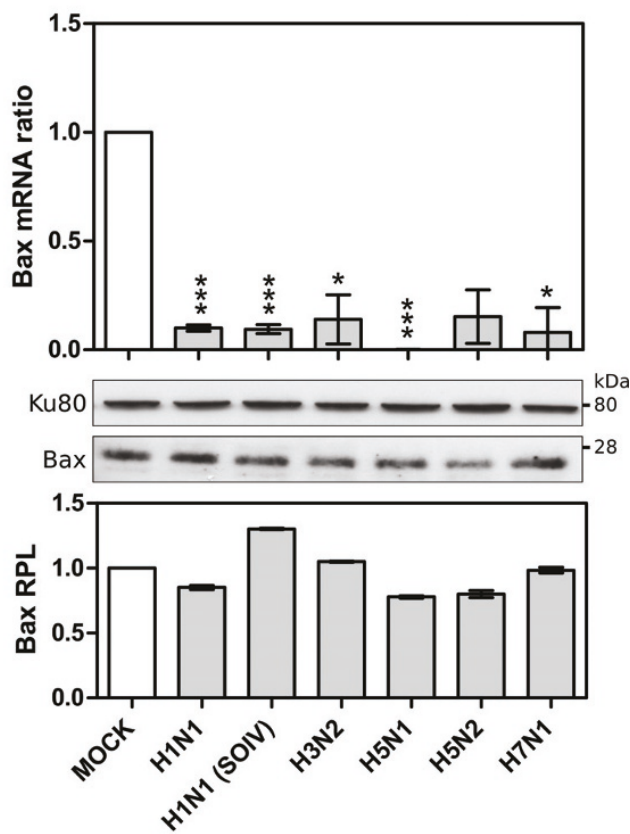

C
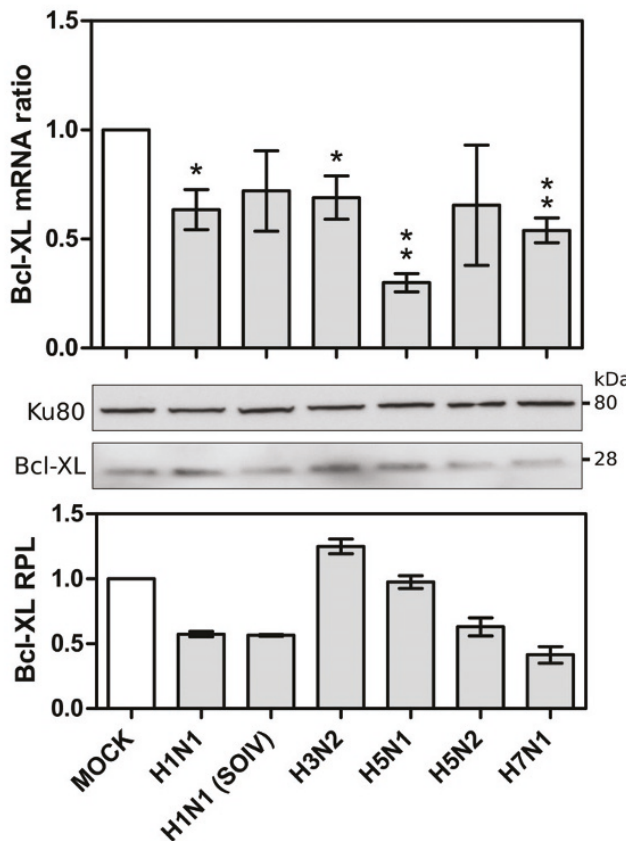

Figure 5 Validation of microarray data by RT-qPCR and western blot: p53 target genes, (A) p21, (B) Bax, (C)Bcl-XL. $\left({ }^{*},{ }^{* *}\right.$ and ${ }^{* * *}$ correspond to $p$-values $<0.05,<0,005,<0.001$, respectively).

only minor changes at the protein level (figure $5 \mathrm{~B}$ ). We also confirmed the down-regulation of $\mathrm{Bcl}-\mathrm{XL}$ expression in cells infected by all viruses except H1N1 SOIV and $\mathrm{H} 5 \mathrm{~N} 2$ (figure $5 \mathrm{C}$ ). At the protein level, Bcl-XL protein level was decreased by most viruses. Of note, the down-regulation of the three p53-target genes, $p 21$,
$B A X$ and $B c l-X L$, was considerably greater in the context of H5N1 infection than with the other influenza A viruses.

Altogether, our results reveal that influenza A infection leads to the down-regulation of several p53 transcriptional targets, at both the mRNA and protein levels 
for some, despite the relative increase in p53 protein levels common for all viruses.

\section{p53 contributes to an antiviral cellular state}

We then wished to assess whether such a global downregulation of the p53 pathway could be associated with a functional effect with regards to viral replication. For this, we compared the production yield of one representative influenza virus (subtype H3N2, circulating strain A/Moscow/10/99) in the HCT116 isogenic cell models (figure 6). HCT116 p53+/+ and p53-/- cells were infected with $\mathrm{H} 3 \mathrm{~N} 2$ at a MOI of $10-3$ and the released viral genome copies were extracted from culture supernatants and quantified by RTqPCR at 24 and $48 \mathrm{hpi}$, as described in materials and methods. The number of genome copies reflecting viral production was 10 and 100 fold higher in HCT116 p53-/- than in HCT116 p53 $+/+$ cells at 24 and $48 \mathrm{~h}$ post-infection, respectively. These results show the effectiveness of p53 protein at slowing down viral production. In agreement with previous reports $[6,25]$, these data suggest the contribution of the p53 protein and associated pathways to the general cellular antiviral response against influenza infection and support the hypothesis that the virally induced global down-regulation of the p53 pathway leads to a cellular state which favours their replication.

\section{Discussion}

A pathway of interest to study influenza interactions with the host cell

In this present study, we report a microarray analysis revealing that infection by four human or avian influenza viruses (H3N2, H5N1, H5N2 and H7N1) significantly alters the gene expression of several host factors

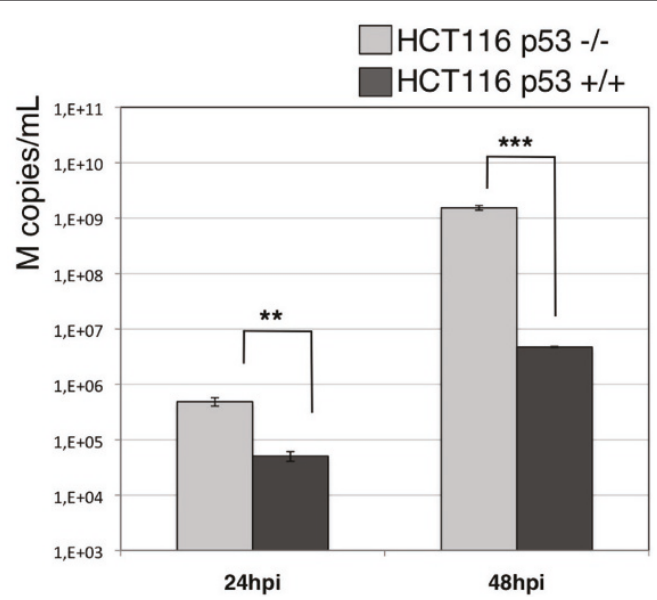

Figure 6 Comparison of viral titres (copies $\mathrm{M} / \mathrm{mL}$ ) produced in HCT116 p53 +/+ or -/- infected with H3N2 A/Moscow/10/99, calculated by RT-qPCR of $\mathrm{M}$ genome copies released in the supernatants. belonging to the p53 pathway. This pathway is composed of numerous genes, the protein products of which have a direct impact on host cell homeostasis, via the regulation of cell death and cell cycle progression as well as several other processes such as metabolism or the cellular immune response [23]. The transcriptional activity of p53 is tightly regulated by $\mathrm{Hdm} 2$ in response to several intracellular signalling cascades triggered by different stimuli (DNA damage, UV irradiation and hypoxia). The central core of the pathway includes the p53 protein itself, which can directly or indirectly shut down the growth of stressed cells mainly by inducing cell-cycle arrest and apoptosis. Considering the central role of the p53 pathway, the impact of influenza infection on this cellular pathway is of particular interest.

Several studies have underlined the interplay between influenza viruses and different cellular signalling pathways, such as the PI3K/Akt, innate immune or apoptotic signalling pathways [4,36-39]. Intriguingly however, only a few have been dedicated to changes in p53 upon influenza infection, highlighting the need to further characterize the interplay between influenza viruses and the p53 pathway $[25,26,34,40]$.

Influenza infection is associated with a global downregulation of signalling cascades both upstream and downstream of $\mathrm{p} 53$ protein

We first observed that upstream signals of the p53 pathway that directly connect stress (UV, hypoxia, DNA damage) -induced signalling cascades to regulators of p53, were generally down-regulated at the transcriptional level by infection. Among such regulating kinases, $D N A-P K, C h k 2, J N K 1$ and Gsk3 $\beta$ genes are all underexpressed following infection.

Similarly, our results also revealed a significant decrease in gene expression for several endogenous p53 transcriptional targets, including $p 21,14-3-3, P E R P$, FAS, DR4/5, PIG3, BAX, Bcl-XL, PAI-1 and PCNA during infection by our set of viruses. Moreover, these results were confirmed at the protein level for p21, Bax and $\mathrm{Bcl}-\mathrm{XL}$.

Altogether, our results indicate a global down-regulation in the mRNA expression of principal factors belonging to both upstream and downstream parts of the p53 pathway, suggesting a global negative effect on p53 pathway activity.

\section{Discrepancy between p53 mRNA, protein levels and activity in influenza infected cells}

The down-regulation of p53-target genes suggests that p53 expression and consequently its transcriptional activity is decreased during infection. We verified whether this was the case using luciferase assay and the monitoring of p53 phosphorylation status by western 
blot in H3N2-infected A549 cells (data not shown) and revealed some discrepancies. On the one hand, no significant change in p53 mRNA expression was detected in infected cells, except for a significant decrease with H5N1. On the other hand, levels of p53 protein expression were significantly increased by all the viruses, seemingly incoherent with the reduced activity of p53 in infected cells.

Altogether, these results suggest a likely complex regulation of TP53 expression during infection. Regulating factors include transcriptional activators (ISGF3 PRKC $\delta$, HOXA5, CREBPB), inhibitors (BCL6, RBPJ) and stabilizing factors (ELAVL1 and ZMAT3) [33]. Influenza infection might therefore induce the over-expression of both inhibitors (BLC6 and RBPJ) and activators (ISGF3) (data not shown). In accordance with this notion, a recent study reported the stress-induced regulation of p53 activity through the control of p53 mRNA stabilization and translation in addition to the well-described alteration of protein stability [33]. Other stabilizing/destabilizing factors, such as host microRNAs may also be involved and should be investigated in the context of infection [33], in particular with $\mathrm{H} 5 \mathrm{~N} 1$, which induces a down-regulation of p53 mRNA expression unlike the other viruses.

Our results also clearly reveal that the impact that influenza viruses have on p53 is not exclusively on gene expression. Further investigations are necessary, in particular on the stabilization and activation of p53 protein, considering the putative interaction of p53 with viral proteins during the time-course of infection.

In this perspective, a recent study reported that the viral protein NS1 interacts with p53 and inhibits its activity [27]. Furthermore, transient expression of H5N1 NS1 (wild-type or with mutations in regions 80-84 and 92) reduced the transcriptional activity of p53 [41]. We can hypothesize that p53 protein is stabilized upon infection in an inactive form through interaction with the viral NS1 protein [27]. Such a scenario would explain our seemingly contradicting results concerning p53 expression and activity. This may even reflect what happens with a number of DNA viruses for which viral proteins like BZLF1 (Epstein Barr Virus) or HBx (Hepatitis $B$ virus) inhibit the transcriptional activity of a stabilized form of p53 [42,43]. Interestingly, the disruption of p53 signalling to p21 was described in human lung A549 cells in the case of BZLF1 viral protein [44].

\section{Viral down-regulation of the $\mathrm{p} 53$ pathway and modulation of the cell cycle and apoptosis by influenza $A$ infection}

We report the down-regulation of the p53-target genes $p 21$ (G1/S-arrest) and 14-3-3 (G2/M-arrest by sequestering Cdc2-complex Cyclin B), both of which are involved in cell cycle control. As expected, the down-regulation of $p 21$ and 14-3-3 in association with an over-expression of the cell-cycle regulators TP53INP1 and GADD45G $[35,45]$, could modulate cell cycle progression and resulted in G1-arrest. Our results are in line with one recent study describing the effect of influenza A infection on the cell cycle and show that viruses can induce an arrest in G0/G1 [46]. They also suggest a putative involvement of p21, TP53INP1 and Gadd45gamma in the influenza-induced cell cycle arrest. A thorough functional evaluation of these results is now needed which should contribute to a better understanding of the viral mechanisms involved which permit an optimal viral protein expression and progeny production.

The other group of down-regulated p53-target genes that we identified during infection encodes the proapoptotic proteins PERP [47], Fas, DR4/5, PIG3 and BAX. In addition, the Bax-inhibiting[48] anti-apoptotic factor Bcl-XL, was also under-expressed during infection, as was PAI-1 whose role in regulating apoptosis remains unclear [49]. At the protein level, Bcl-XL expression was decreased by most viral infections. It is worth noting that the down-regulation of the three $\mathrm{p} 53$ target genes, $p 21, B A X$ and $B c l-X L$, was considerably greater after $\mathrm{H} 5 \mathrm{~N} 1$ infection than with the other influenza A viruses tested.

Concordantly, the knock-down of $B A X$ was recently shown to reduce the replication of influenza virus [50]. Thus the down-regulation of a negative regulator of Bax, such as the anti-apoptotic Bcl-XL, at both mRNA and protein levels, such as we have reported here, would be expected to increase viral replication. Further silencing experiments are required to confirm such a result.

Altogether, our observations suggest that influenza viruses may at least partially control intrinsic and extrinsic pathways of apoptosis by decreasing the expression of both pro- and anti-apoptotic factors which are under the control of the p53 transcription factor, as suggested by several studies [39].

\section{Is inhibition of the p53 pathway essential for the replication cycle of influenza viruses?}

In agreement with the above hypothesis, we showed that the level of $\mathrm{H} 3 \mathrm{~N} 2$ viral production is significantly higher in HCT116 p53 -/- than in HCT116 p53 +/+ cells, at both 24 and 48 hpi (figure 6). These results are in accordance with initial observations reported by Turpin and colleagues in a p53 dominant-negative A549 model and more recent data reported on siRNA high-throughput screening for host functional interactants $[25,6]$.

These and our results suggest a marked antiviral facet for p53 and its pathway in the context of influenza infection, as has already been observed for several other 
viruses. The antiviral effect of p53 depends largely on its pro-apoptotic activity, which limits virus replication [51]. However, other works have also demonstrated that p53 contributes to the innate cellular antiviral response by enhancing type I interferon (IFN)-dependent antiviral activity, independently of its function as a pro-apoptotic gene [52]. In light of our results on p53 targets implicated in cell-cycle regulation and a recent study on human circulating leukocytes from infected patients [53], the p53 antiviral role might involve not only its activity in mediating the IFN response and apoptosis, but also in controlling cell cycle progression.

\section{Conclusions}

In conclusion, the p53 pathway is inhibited during infection by influenza A, either by the control over the expression of key p53 stabilizing factors, as is the case with H3N2, H5N1, H5N2 and H7N1, or by the decrease in p53 mRNA levels as is the case with H5N1. In accordance with an overall decrease of p53 activity, the global down-regulation of p53-target genes could contribute to changes in both the apoptotic response and cell-cycle progression, altogether inducing a pro-viral cellular context. The present study has highlighted the p53 pathway as an important player in influenza infection. Further investigations are now needed to discriminate the cellular antiviral response from the viral hijacking of the p53 pathway during the time-course of infection.

\section{Fundings}

This work was supported by University Claude Bernard of Lyon, the Civil hospitals of Lyon, the AVIESAN alliance and by a grant of the "Programme de Recherche A (H1N1)" co-ordinated by the Institut de Microbiologie et Maladies Infectieuses (INSERM). The funders had no role in study design, data collection and analysis, decision to publish, or preparation of the manuscript.

\footnotetext{
Author details

${ }^{1}$ Laboratoire de Virologie et Pathologie Humaine VirPath, Université Claude Bernard Lyon 1, Université de Lyon, Lyon, France. ${ }^{2}$ Division of Medical Sciences, Centre for Oncology and Molecular Medicine, University of Dundee, Ninewells Hospital, Dundee, Scotland, UK. ${ }^{3}$ Laboratoire de Virologie Centre de Biologie et de Pathologie Est, Hospices Civils de Lyon, Lyon, France. ${ }^{4}$ Institut National de la Santé et de la Recherche Médicale (INSERM) U928 Technologies Avancées pour le Génome et la Clinique, Université de la Méditerranée, Marseille, France. ${ }^{5}$ Centre National de la Recherche Scientifique (CNRS) UMR 5534, Centre Léon Bérard, Centre de Génétique Moléculaire et Cellulaire, Université Lyon 1, Lyon, France.
}

\section{Authors' contributions}

$\mathrm{TO}$ and $\mathrm{L} J$ carried out the experiments and the analysis of results. TO, $L J$ and MRC wrote the manuscript. GC and OF participated in the design of the study and performed viral infections in the human lung carcinoma A549 cellular model. JT supervised the transcriptomic analysis. CN, JJD, BL, VM and JCB participated to the conception and coordination of the study and helped to write the manuscript. MRC managed the investigations. All authors read and approved the final manuscript.

\section{Competing interests}

The authors declare that they have no competing interests.

Received: 5 April 2011 Accepted: 8 June 2011 Published: 8 June 2011

\section{References}

1. Palese $P$, Shaw M: Orthomyxoviridae: the viruses and their replication. In Fields Virology.. 5 edition. Edited by: Knipe D, Howley PM. Philadelphia, PA: Lippincott Williams 2007:1647-1689.

2. Neumann G, Noda T, Kawaoka Y: Emergence and pandemic potential of swine-origin H1N1 influenza virus. Nature 2009, 459:931-939.

3. Webster RG, Bean WJ, Gorman OT, Chambers TM, Kawaoka Y: Evolution and ecology of influenza A viruses. Microbiol. Rev 1992, 56:152-179.

4. Ludwig S, Pleschka S, Planz O, Wolff T: Ringing the alarm bells: signalling and apoptosis in influenza virus infected cells. Cell. Microbiol 2006, 8:375-386.

5. Geiss GK, An MC, Bumgarner RE, Hammersmark E, Cunningham D, Katze MG: Global impact of influenza virus on cellular pathways is mediated by both replication-dependent and -independent events. J. Virol 2001, 75:4321-4331.

6. Shapira SD, Gat-Viks I, Shum BOV, Dricot A, de Grace MM, Wu L, Gupta PB, Hao T, Silver SJ, Root DE, Hill DE, Regev A, Hacohen N: A physical and regulatory map of host-influenza interactions reveals pathways in $\mathrm{H} 1 \mathrm{~N} 1$ infection. Cell 2009, 139:1255-1267.

7. Kobasa D, Jones SM, Shinya K, Kash JC, Copps J, Ebihara H, Hatta Y, Kim JH, Halfmann P, Hatta M, Feldmann F, Alimonti JB, Fernando L, Li Y, Katze MG, Feldmann $H$, Kawaoka Y: Aberrant innate immune response in lethal infection of macaques with the 1918 influenza virus. Nature 2007, 445:319-323.

8. Kash JC, Basler CF, García-Sastre A, Carter V, Billharz R, Swayne DE, Przygodzki RM, Taubenberger JK, Katze MG, Tumpey TM: Global host immune response: pathogenesis and transcriptional profiling of type $A$ influenza viruses expressing the hemagglutinin and neuraminidase genes from the 1918 pandemic virus. J. Virol 2004, 78:9499-9511.

9. J-ichi Kawada, Kimura H, Kamachi Y, Nishikawa K, Taniguchi M, Nagaoka K, Kurahashi H, Kojima S, Morishima T: Analysis of gene-expression profiles by oligonucleotide microarray in children with influenza. J. Gen. Virol 2006, 87:1677-1683.

10. Schmolke M, Viemann D, Roth J, Ludwig S: Essential impact of NF-kappaB signaling on the H5N1 influenza A virus-induced transcriptome. J. Immunol 2009, 183:5180-5189.

11. Ludwig S, Planz O, Pleschka S, Wolff T: Influenza-virus-induced signaling cascades: targets for antiviral therapy? Trends Mol Med 2003, 9:46-52.

12. Ehrhardt C, Seyer R, Hrincius ER, Eierhoff T, Wolff T, Ludwig S: Interplay between influenza $A$ virus and the innate immune signaling. Microbes Infect 2010, 12:81-87.

13. Cameron CM, Cameron MJ, Bermejo-Martin JF, Ran L, Xu L, Turner PV, Ran R, Danesh A, Fang Y, Chan P-KM, Mytle N, Sullivan TJ, Collins TL, Johnson MG, Medina JC, Rowe T, Kelvin DJ: Gene expression analysis of host innate immune responses during Lethal H5N1 infection in ferrets. J. Virol 2008, 82:11308-11317

14. Baskin CR, Bielefeldt-Ohmann H, Tumpey TM, Sabourin PJ, Long JP, GarcíaSastre A, Tolnay AE, Albrecht R, Pyles JA, Olson PH, Aicher LD, Rosenzweig ER, Murali-Krishna K, Clark EA, Kotur MS, Fornek JL, Proll S, Palermo RE, Sabourin CL, Katze MG: Early and sustained innate immune response defines pathology and death in nonhuman primates infected by highly pathogenic influenza virus. Proc. Natl. Acad. Sci. USA 2009, 106:3455-3460.

15. Josset L, Textoris J, Loriod B, Ferraris O, Moules V, Lina B, N'guyen C, Diaz JJ, Rosa-Calatrava M: Gene expression signature-based screening identifies new broadly effective influenza a antivirals. PLOS ONE 2010, 5(10):e13169, 2010 Oct 4.

16. Bunz F, Dutriaux A, Lengauer C, Waldman T, Zhou S, Brown JP, Sedivy JM, Kinzler KW, Vogelstein B: Requirement for p53 and p21 to sustain G2 arrest after DNA damage. Science 1998, 282:1497-1501.

17. Moules V, Ferraris $\mathrm{O}$, Terrier $\mathrm{O}$, Giudice $\mathrm{E}$, Yver M, Rolland JP, BouscambertDuchamp M, Bergeron C, Ottmann M, Fournier E, Traversier A, Boule C, Rivoire A, Lin Y, Hay A, Valette M, Marquet R, Rosa-Calatrava M, Naffakh N, Schoehn G, Thomas D, Lina B: In vitro characterization of naturally occurring influenza H3NA- viruses lacking the NA gene segment: toward a new mechanism of viral resistance? Virology 2010, 404:215-224. 
18. Tusher VG, Tibshirani R, Chu G: Significance analysis of microarrays applied to the ionizing radiation response. Proc. Natl. Acad. Sci. USA 2001, 98:5116-5121.

19. Schwender $\mathrm{H}$, Ickstadt $\mathrm{K}$ : Empirical Bayes analysis of single nucleotide polymorphisms. BMC Bioinformatics 2008, 9:144.

20. Samarajiwa SA, Forster S, Auchettl K, Hertzog PJ: INTERFEROME: the database of interferon regulated genes. Nucleic Acids Res 2009, 37: D852-857.

21. Schmittgen TD, Livak KJ: Analyzing real-time PCR data by the comparative C(T) method. Nat Protoc 2008, 3:1101-1108.

22. Duchamp MB, Casalegno JS, Gillet $Y$, Frobert E, Bernard E, Escuret $V$, Billaud G, Valette M, Javouhey E, Lina B, Floret D, Morfin F: Pandemic A (H1N1)2009 influenza virus detection by real time RT-PCR: is viral quantification useful? Clin. Microbiol. Infect 2010, 16:317-321.

23. Vousden KH, Lane DP: p53 in health and disease. Nat. Rev. Mol. Cell Biol 2007, 8:275-283

24. Muñoz-Fontela C, Macip S, Martínez-Sobrido L, Brown L, Ashour J, GarcíaSastre A, Lee SW, Aaronson SA: Transcriptional role of p53 in interferonmediated antiviral immunity. J. Exp. Med 2008, 205:1929-1938.

25. Turpin E, Luke K, Jones J, Tumpey T, Konan K, Schultz-Cherry S: Influenza virus infection increases p53 activity: role of p53 in cell death and viral replication. J. Virol 2005, 79:8802-8811.

26. Zhirnov OP, Klenk HD: Control of apoptosis in influenza virus-infected cells by up-regulation of Akt and p53 signaling. Apoptosis 2007, 12:1419-1432.

27. Wang X, Shen Y, Qiu Y, Shi Z, Shao D, Chen P, Tong G, Ma Z: The nonstructural (NS1) protein of influenza A virus associates with p53 and inhibits p53-mediated transcriptional activity and apoptosis. Biochem. Biophys. Res. Commun 2010, 395:141-145.

28. Meek DW, Anderson CW: Posttranslational modification of p53: cooperative integrators of function. Cold Spring Harb Perspect Biol 2009, 1: a000950.

29. Haupt $Y$, Maya R, Kazaz A, Oren M: Mdm2 promotes the rapid degradation of p53. Nature 1997, 387:296-299.

30. Kubbutat $\mathrm{MH}$, Jones $\mathrm{SN}$, Vousden $\mathrm{KH}$ : Regulation of p53 stability by Mdm2. Nature 1997, 387:299-303.

31. Fayard E, Xue G, Parcellier A, Bozulic L, Hemmings BA: Protein kinase B (PKB/Akt), a key mediator of the PI3K signaling pathway. Curr. Top. Microbiol. Immunol 2010, 346:31-56.

32. Hale BG, Jackson D, Chen YH, Lamb RA, Randall RE: Influenza A virus NS1 protein binds p85beta and activates phosphatidylinositol-3-kinase signaling. Proc. Natl. Acad. Sci. USA 2006, 103:14194-14199.

33. Vilborg A, Wilhelm MT, Wiman KG: Regulation of tumor suppressor p53 at the RNA level. J. Mol. Med 2010, 88:645-652

34. Shen Y, Wang X, Guo L, Qiu Y, Li X, Yu H, Xiang H, Tong G, Ma Z: Influenza $A$ virus induces $\mathrm{p} 53$ accumulation in a biphasic pattern. Biochem. Biophys. Res. Commun 2009, 382:331-335.

35. Tomasini R, Seux M, Nowak J, Bontemps C, Carrier A, Dagorn JC, Pébusque MJ, lovanna $J$, Dusetti NJ: TP53INP1 is a novel p73 target gene that induces cell cycle arrest and cell death by modulating p73 transcriptional activity. Oncogene 2005, 24:8093-8104.

36. Ehrhardt C, Ludwig S: A new player in a deadly game: influenza viruses and the PI3K/Akt signalling pathway. Cell. Microbiol 2009, 11:863-871.

37. Ehrhardt C, Seyer R, Hrincius ER, Eierhoff T, Wolff T, Ludwig S: Interplay between influenza $A$ virus and the innate immune signaling. Microbes Infect 2010, 12:81-87.

38. Watanabe T, Watanabe S, Kawaoka Y: Cellular networks involved in the influenza virus life cycle. Cell Host Microbe 2010, 7:427-439.

39. Lowy RJ: Influenza virus induction of apoptosis by intrinsic and extrinsic mechanisms. Int. Rev. Immunol 2003, 22:425-449.

40. Technau-Ihling K, Ihling C, Kromeier J, Brandner G: Influenza A virus infection of mice induces nuclear accumulation of the tumorsuppressor protein p53 in the lung. Arch. Virol 2001, 146:1655-1666.

41. Li W, Wang G, Zhang H, Xin G, Zhang D, Zeng J, Chen X, Xu Y, Cui Y, Li K Effects of NS1 variants of H5N1 influenza virus on interferon induction, TNFalpha response and p53 activity. Cell. Mol. Immunol 2010, 7:235-242.

42. Collot-Teixeira S, Bass J, Denis F, Ranger-Rogez S: Human tumor suppressor p53 and DNA viruses. Rev. Med. Virol 2004, 14:301-319.

43. Levine AJ: The common mechanisms of transformation by the small DNA tumor viruses: The inactivation of tumor suppressor gene products: p53. Virology 2009, 384:285-293.
44. Mauser A, Saito S, Appella E, Anderson CW, Seaman WT, Kenney S: The Epstein-Barr virus immediate-early protein BZLF1 regulates p53 function through multiple mechanisms. J. Virol 2002, 76:12503-12512.

45. Vairapandi M, Balliet AG, Hoffman B, Liebermann DA: GADD45b and GADD45g are cdc2/cyclinB1 kinase inhibitors with a role in $S$ and G2/M cell cycle checkpoints induced by genotoxic stress. J. Cell. Physiol 2002, 192:327-338.

46. He Y, Xu K, Keiner B, Zhou J, Czudai V, Li T, Chen Z, Liu J, Klenk HD, Shu YL, Sun B: Influenza A virus replication induces cell cycle arrest in G0/G1 phase. J. Virol 2010, 84:12832-12840.

47. Attardi LD, Reczek EE, Cosmas C, Demicco EG, McCurrach ME, Lowe SW, Jacks T: PERP, an apoptosis-associated target of p53, is a novel member of the PMP-22/gas3 family. Genes Dev 2000, 14:704-718.

48. Leber B, Lin J, Andrews DW: Still embedded together binding to membranes regulates $\mathrm{Bcl}-2$ protein interactions. Oncogene 2010 29:5221-5230.

49. Lademann UA, Rømer MU: Regulation of programmed cell death by plasminogen activator inhibitor type 1 (PAl-1). Thromb. Haemost 2008, 100:1041-1046

50. McLean JE, Datan E, Matassov D, Zakeri ZF: Lack of Bax prevents influenza A virus-induced apoptosis and causes diminished viral replication. J. Virol 2009, 83:8233-8246.

51. Takaoka A, Hayakawa S, Yanai H, Stoiber D, Negishi H, Kikuchi H, Sasaki S, Imai K, Shibue T, Honda K, Taniguchi T: Integration of interferon-alpha/ beta signalling to $\mathrm{p} 53$ responses in tumour suppression and antiviral defence. Nature 2003, 424:516-523.

52. Muñoz-Fontela C, Macip S, Martínez-Sobrido L, Brown L, Ashour J, GarcíaSastre A, Lee SW, Aaronson SA: Transcriptional role of p53 in interferonmediated antiviral immunity. J. Exp. Med 2008, 205:1929-1938.

53. Parnell G, McLean A, Booth D, Huang S, Nalos M, Tang B: Aberrant cell cycle and apoptotic changes characterise severe influenza a infection - a meta-analysis of genomic signatures in circulating leukocytes. PLOS ONE 2011, 6:e17186.

doi:10.1186/1743-422X-8-285

Cite this article as: Terrier et al:: Cellular transcriptional profiling in human lung epithelial cells infected by different subtypes of influenza A viruses reveals an overall down-regulation of the host p53 pathway. Virology Journal 2011 8:285.

\section{Submit your next manuscript to BioMed Central and take full advantage of:}

- Convenient online submission

- Thorough peer review

- No space constraints or color figure charges

- Immediate publication on acceptance

- Inclusion in PubMed, CAS, Scopus and Google Scholar

- Research which is freely available for redistribution

Submit your manuscript at www.biomedcentral.com/submit
C Biomed Central 